\title{
Preschool Children's Representation of Numbers on a Linear Number Line: Implications to Teaching and Learning of Number Concepts
}

\author{
Munirah Ghazali ${ }^{1}$, Ayminsyadora Ayub ${ }^{1}$, Abdul Razak Othman ${ }^{2}$ \\ ${ }^{1}$ School of Educational Studies, Universiti Sains Malaysia,Malaysia \\ ${ }^{2}$ Institut Pendidikan Guru Kampus Tuanku Bainun, Malaysia
}

\begin{abstract}
A basic challenge in understanding human cognitive development is to understand how children acquire number concepts. The Hindu-Arabic number system represents amounts of objects by number symbols, without referring to other properties of these objects (e.g., color, size). That is to say that the number symbols, like many other symbols, are linked to the objects that they represent in an arbitrary but agreed upon manner with fixed representation rules. Therefore, when the number system is used in a teaching-learning process, the child is required to perform a relatively complicated cognitive process. This paper reports on a research project that was carried out to investigate preschool children's mapping of numbers onto the linear number lines. A total of thirty 5 and 6 year old preschool children were interviewed individually in a number-space task with three sets of number lines that is $1-10,1-20$ and $1-100$. Preliminary findings suggest that children understood the task and adopted a consistent strategy of mapping consecutive numbers onto consecutive location. Implications of the findings to the teaching of mathematics at preschool level will be discussed.
\end{abstract}

Keywords: Number concepts, Number line, Representation

\section{INTRODUCTION}

Researchers have demonstrated that children begin to think mathematically from an early age. Many children arrive at primary school already equipped with an extraordinary understanding of the number system and how it works (Wright, 1994; Young-Loveridge, 2004). More specifically, research has indicated a strong relationship between the frequency of early experiences and later performance in school mathematics (BlevinsKnabe \& Musun-Miller, 1996; Dearing, McCartney, \& Taylor, 2009; Jordan, Kaplan, Ramineni, \& Locuniak, 2009; LeFevre et al., 2009). Furthermore, the earliest stages of learning mathematics are foundational for future learning and attainment of mathematics across grades, Baroody (2009). In fact, current studies have found that a child's performance prior to primary school predicts learning of mathematical concepts up to high school (Duncan et al., 2007. Such research strongly suggests children's experiences at home or preschool form the foundation for mathematical learning in school.

A basic challenge in understanding children's mathematical knowledge is to understand how children acquire number concepts. Children show numerical abilities long before language acquisition and formal education. It is widely believed that numeracy is founded upon an early non-symbolic system of numerical representation (Feigenson, Dehaene, \& Spelke, 2004; Carey, 2001). Numerical acuity is progressively refined throughout childhood, attaining adult's ability in early adolescence (Halberda \& Feigenson, 2008). With language acquisition, children understand how number words map onto distinct numerosities (Wynn, 1996), first in their counting range and then also outside of it (Lipton \& Spelke, 2006). The Hindu-Arabic number system represents amounts of objects by number symbols, without referring to other properties of these objects (e.g., color, size). That is to say that the number symbols, like many other symbols, are linked to the objects that they represent in an arbitrary but agreed upon manner with fixed representation rules (Vygotsky, 1978). Therefore, when the number system is used in a teaching-learning process, the child is required to perform a relatively complicated cognitive process. He or she has to refer to the meaning behind the symbols and to make the connections between the symbols and the quantities (Kaput, 1991; Lesh \& Doerr, 2000, Thomas, Jolley, Robinson \& Champion, 1999). The development of symbolic thinking addresses the cognitive processes that take place in the structure of the mental representation during the change from the "unity level" to that of the "differentiation level" (Nemirovsky \& Monk, 2000).

Behr, Lesh, Post, \& Silver, 1983; Lesh, 1981; Lesh, Landau, \& Hamilton, 1983) have identified five distinct types of representation systems that occur in mathematics learning and problem solving as seen in figure 1. They are: (1) experience based "scripts"-in which knowledge is organized around "real world" events that 
serve as general contexts for interpreting and solving other kinds of problem situations; (2) manipulatable models-like Cuisenaire rods, arithmetic blocks, fraction bars, number lines, etc., in which the "elements" in the system have little meaning per se, but the "built in" relationships and operations fit many everyday situations; (3) pictures or diagrams-static figural models that, like manipulatable models, can be internalized as "images"; (4) spoken languages-including specialized sub languages related to domains like logic, etc.; (5) written symbols-which, like spoken languages, can involve specialized sentences and phrases $\left(\mathrm{X}+3=7, \mathrm{~A}^{\prime} \mathrm{UB}^{\prime}=\right.$ $\left.(\mathrm{AnB})^{\prime}\right)$ as well as normal sentences and phrases.



Fig1: Representations and connections (Behr, Lesh, Post, \& Silver, 1983; Lesh, 1981; Lesh, Landau, \& Hamilton, 1983)

\section{Number Concepts In The Preschool ANd Early Primary Year's Curriculum}

The Malaysian preschool curriculum for mathematics focus on the development of logical mathematical thinking through manipulation of concrete objects, inculcate inquisitive and investigate skills as well as to develop problem solving skills in everday life(Kementerian Pendidikan Malaysia, 2003). There are eleven major elements in the preschool mathematics namely classification, seriation, matching, number concepts, number operations, measurement, comparing dan discriminating observation, making prediction, time, space and problem solving.

The mathematical understanding and skills acquired are further developed in the primary schools. The primary school mathematics curriculum aims to build students' understanding of number concepts and their basic skills in computation that they can apply in their daily routines effectively and responsibly in keeping with the aspirations of a developed society and nation, and at the same time to use this knowledge to further their studies (Huraian Sukatan Pelajaran, 2003). In summary, the aim of the primary grade mathematics is to enable the child to acquire mastery in the basic skills and that these skills are to be applied constantly to the child's real life experiences. Problem solving is emphasised throughout the curriculum. Number concepts are weaved in the concepts especially in the four basic operation namely addition, subtraction, multiplication and division. The curriculum indicates that in Year 1, the operations are for numbers with the highest total of 18, and subtraction within the range of 18 where they are expected to recall rapidly basic facts of addition, basic facts of subtraction, and the total of two numbers and the difference of two numbers. The current KSSR or Primary School Standard Curriculum actually stated that Year 1 students are expected to know numbers from 1 to 100 . Similarly, in Year 2 addition and subtraction are covered in addition with the highest total of 1000 and subtraction within the range of 1000 with different combinations of one digit, two digit and three digits numbers. In Year 3, the four basic operations are covered in addition with the highest total of 10000 and subtraction within the range of 10000 where students are expected to be able to add and subtract two numbers up to four digits.

\section{REPRESENTATIONS AND UNDERSTANDING}

Researchers draw strong connections between the representations children use and their understanding (Lamon, 2001). Janvier (1987) describes understanding as a "cumulative process mainly based upon the capacity of dealing with an 'everenriching'set of representations". Furthermore, representations are considered as a means in the formation of conceptual understanding. The ability to move smoothly between various representations of the same concept is seen as an indication of conceptual understanding and also as a goal for instruction (Lesh, Behr and Post, 1987). Moreover, according to Kaput (1991), possessing an abstract mathematical concept 'is better regarded as a notationally rich web of representations and applications'.

The mapping of numbers onto space plays an essential role in mathematics, from measurement and geometry to the study of irrational numbers, Cartesian coordinates, the real number line and the complex plane (Dehaene, 1997). Research documents a remarkable shift in the child's conception of how numbers map onto space (Booth \& Siegler, 2006; Siegler \& Opfer, 2003). When asked to point towards the correct location for a 
spoken number word onto a line segment labeled with 0 at left and 100 at right, even preschool children understand the task and behave non-randomly, systematically placing smaller numbers at left and larger numbers at right. They do not distribute the numbers evenly, however, and instead devote more space to small numbers, imposing a compressed, logarithmic mapping. For instance they might place number 10 near the middle of the $0-100$ segment. Numerous recent studies using estimation tasks and other tasks that require translation of numerical stimuli indicate that children consistently progress from logarithmic representations of numerical magnitudes to linear representations. This is evident in whole number estimation, fraction estimation.

This paper investigates specifically the representations of numerical magnitudes on a number line. Such representations are central to understanding the meaning of number symbols (e.g., knowing that " 6 " denotes six objects), to comparing the magnitudes of numbers (e.g., knowing that six is more than four), and to estimating quantities (e.g., knowing whether there are 6, 60, or 600 candies in a jar). Development of numerical magnitude representations is an important educational problem, because the process causes many students difficulty and because immature numerical magnitude representations hinder these students' learning of mathematics. Numerical estimation tasks have proved particularly useful for providing insights into numerical magnitude representations. As noted in Siegler and Booth's (2004) review of the estimation literature, numerical estimation is a process of translating between alternative quantitative representations, at least one of which is inexact and at least one of which is numerical. For example, number-line estimation requires translating a number into a spatial position on a number line or translating a spatial position on a number line into a number.

\subsection{Participants.}

\section{METHODOLOGY}

Thirty children ages five and six from a preschool in Pulau Pinang took part in this research. Children were divided into two groups according to their ages.

\subsection{Procedure.}

A trained research officer met individually with the children during school hours in a quiet room. Children were presented with $25 \mathrm{~cm}$ long lines in the center of white A4 sheets. Three different intervals were administered: $1-10,1-20$ and $1-100$. All numbers except for 1,5 , and 10 had to be positioned on the smaller interval, whereas for the larger interval numbers were 2, 3, 4, 6, 18, 25, 48, 67, 71, and 86 (corresponding to Sets A and B for the same interval in Siegler \& Opfer,2003).

Problems were blocked so that within a session, each interval were presented as a block meaning that the researcher show the number line 1-10 and requested the students to mark the line as the researcher said a particular number. Children answered all the problems on the 1-10 interval before any of the problems on the 1-20 interval and 1-100 interval. Before each item, the experimenter said, "This number line goes from 1 at this end to $10[20,100]$ at this end. If this is 1 and this is $10[20,100]$, where would you put $N$ ?" (with $N$ being the number specified on the particular trial). In order to create a game like situation, the researcher actually printed each numbers on a stick-on paper and children were asked to paste the number written on the sticker onto the given interval.

\section{RESULTS AND DISCUSSION}

Children's estimation accuracy was computed as percentage of absolute error (PE). This was calculated with the following equation (Siegler \& Booth, 2004):

$$
\mathrm{PE}=\left|\begin{array}{c}
\text { estimate }- \text { target number } \\
\text { Scale of estimates }
\end{array}\right| \times 100
$$

For example, if the estimated position of 30 on the $0-100$ interval corresponds to 45 , the PE would be $15 \%$; that is $[(45-30) / 100] \times 100$. A one way analysis of variance (ANOVA) on mean PE was computed for each interval, with age as between subject factor. For all the three intervals, results indicated that the PE for the two age groups were significantly different for intervals 1-20 and 1-100 but not for the 1-10 interval as shown in table 1

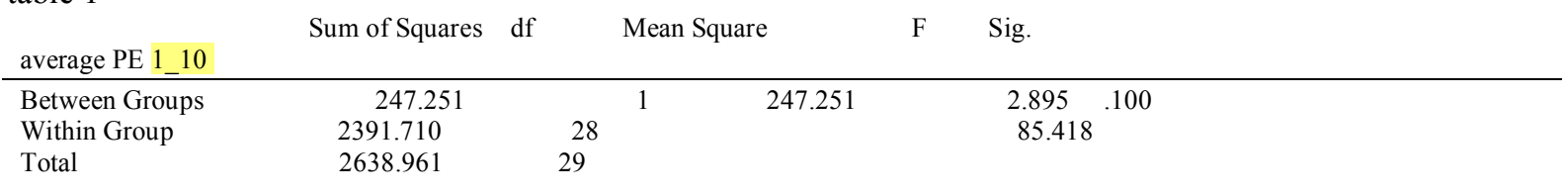




\begin{tabular}{|c|c|c|c|c|}
\hline Between Groups & 2205.442 & 1 & $2205.442 \quad 1$ & $6.619 \quad .000$ \\
\hline Within Groups & 3715.751 & & 28 & 132.705 \\
\hline Total & 5921.193 & 29 & & \\
\hline \multicolumn{5}{|l|}{ average $P E$ for $1-100$} \\
\hline Between Groups & 802.901 & 1 & 802.901 & $10.312 \quad .003$ \\
\hline Within Groups & 2180.093 & 28 & 77.860 & \\
\hline Total & 2982.995 & 29 & & \\
\hline
\end{tabular}

Table 1: ANOVA on mean PE for intervals 1-10, 1-20 and 1-100

The accuracy of estimation increased with age for all the three intervals as indicated in table 2 :

\begin{tabular}{|c|c|c|c|}
\hline Age & Average PE 1-10 & Average PE 1-10 & Average PE $1-100$ \\
\hline $\begin{array}{l}5 \text { year olds } \\
\text { mean }\end{array}$ & 17.31 & 25.89 & 29.63 \\
\hline $\begin{array}{l}6 \text { year olds } \\
\text { mean }\end{array}$ & 11.57 & 8.74 & 19.28 \\
\hline
\end{tabular}

Table 2: Average PE percentage error according to age and intervals

The initial analysis in examined the fit of linear and logarithmic functions to the median estimates of children, grouped by age for each of the numbers in the given interval. Following Siegler and Booth, 2004, medians rather than means were used to minimize the effect of outliers. The medians of the absolute distances between children's median estimate for each number and (a) the predicted values according to the best linear model and (b) the predicted values according to the best logarithmic model. For the 1-10 interval, the model with the highest R2 was the linear model for both five and six year olds. For the 1-20 and 1-100 interval, the model with the highest R2 was the logarithmic models for the preschool children in this study.

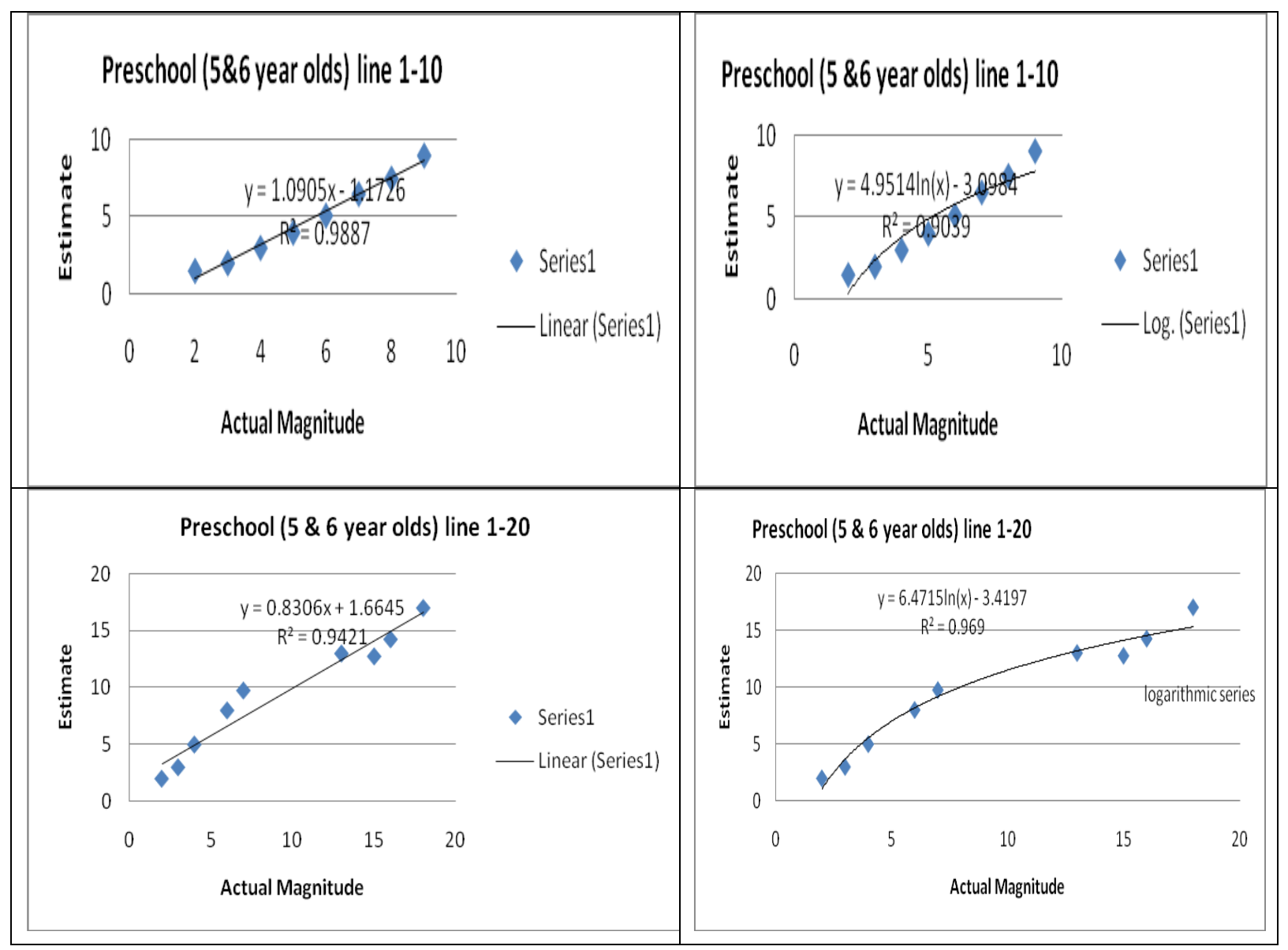






Fig.2: Median Estimate versus actual magnitude with best linear and logarithmic model

\section{Conclusion}

Development of numerical magnitude representations is an important educational problem, because the process causes many students difficulty and because immature numerical magnitude representations hinder these students' learning of mathematics. Numerical estimation tasks have proved particularly useful for providing insights into numerical magnitude representations. Developmental shifts from a logarithmic to a linear representation have in fact been found between kindergarten and second grade for estimates of numerical 
locations on 0-100 number lines (Siegler \& Booth, 2004) and between second and sixth grade for estimates of numerical locations on $0-1000$ lines (Siegler \& Opfer, 2003). Thus, when asked to estimate the locations of numbers on number lines with 0 at one end and 100 at the other and no markings in between, most preschool children produced estimates consistent with a logarithmic function. The findings from this small scale research raised more questions than answers such as whether the shift from a logarithmic to a linear representation occur naturally as a child mature or could teaching and learning activities be designed to facilitate the shift. Furthermore, it is important for preschool teachers to be aware of preschool students' magnitude representation thus facilitate the teaching and learning process.

\section{REFERENCES}

[1] Wright, R. J. (1994). A study of the numerical development of 5-year-olds and 6-yearolds. Educational Studies in Mathematics, 26, 25-44.

[2] Young-Loveridge, J. M. (2004). Effects on early numeracy of a program using number books and games. Early Childhood Research Quarterly, 19, 82-98

[3] Blevins-Knabe, B., \& Musun-Miller, L. (1996). Number use at home by children and their parents and its relationship to early mathematical room. Early Development and Parenting, 5(1), 35-45.

[4] Dearing, E., McCartney, K., \& Taylor, B.A. (2009). Does higher quality early child care promote low-income children's math and reading achievement in middle childhood? Child Development, 80, 1329-1349. doi: 10.1111/j.1467-8624.2009.01336.x

[5] Jordan, N.C., Kaplan, D., Ramineni,C., \& Locuniak, M.N. (2009). Early math matters: Kindergarten number competence and later mathematics outcomes. Developmental Psychology, 45(3), 850-867.

[6] LeFevre, J. , Skwarchuk, S. , Smith-Chant, B. L. , Fast, L. , Kamawar, D. and Bisanz, J. (2009) Home numeracy experiences and children's math performance in the early school years. Canadian Journal of Behavioural Science 41, pp. 55-66.

[7] Baroody, A. J. (2009). Fostering early numeracy in preschool and kindergarten. Encyclopedia of Language and Literacy Development (pp. 1-10). London, ON: Canadian Language and Literacy Research Network.

[8] Duncan, G. J., Dowsett, C. J., Claessens, A., Magnuson, K., Huston, A. C., Klebanov, P., et al. (2007). School readiness and later achievement. Developmental Psychology, 43(6), 1428-1446.

[9] Feigenson, L., Dehaene, S., \& Spelke, E. (2004). Core system of number. Trends in Cognitive Sciences, 8, $307-314$.

[10] Carey, S. (2001). Cognitive foundations of arithmetic: Evolution andontogenesis. Mind \& Language, 16, 37-55.

[11] Halberda, J., \& Feigenson, L. (2008). Developmental change in the acuity of the "number sense": The approximate number system in 3-, 4-, 5-, and 6-year-olds and adults. Developmental Psychology, 44, 1457-1465

[12] Wynn, K. (1996). Infants' individuation and enumeration of actions. Psychological Science, 7, $164-169$.

[13] Lipton, J., \& Spelke, E. (2006). Preschool children master the logic of number words meanings. Cognition, 98, B57-B66

[14] Vygotsky, L. S. (1978). Mind in society: The development of higher psychological processes. Cambridge, MA: Harvard University Press.

[15] Kaput, J. (1991). Notations and representations as mediators of constructive processes. In E. von Glaserfeld (Ed.), Radical constructivism in mathematics education (pp. 53-74). Dordrecht, Netherlands: Kluwer Academic Publishers.

[16] Lesh, R., \& Doerr, H. M. (2000). Symbolizing, communicating, and mathematizing: Key components of models and modeling. In P. Coob, E. Yackel, \& K. McClain (Eds.), Symbolizing and communicating in mathematics classrooms: Perspectives on discourse, tools, and instructional design (pp. 361-384). Mahwah, New Jersey: Lawrence Erlbaum Associates

[17] Thomas, G. V., Jolley, R. P., Robinson, E. J., \& Champion, H. (1999). Realist errors in children's responses to pictures and words as representations. Journal of Experimental Child Psychology, 74, 1-20.

[18] Nemirovsky, R., \& Monk, S. (2000). "If you look at it the other way ...": an exploration into the nature of symbolizing. In P. Coob, E. Yackel, \& K. McClain (Eds.), Symbolizing and communicating in mathematics classrooms: Perspectives on discourse, tools, and instructional design (pp. 177-224). Mahwah, New Jersey: Lawrence Erlbaum Associates.

[19] Behr. M., Lesh, R.. Post, T., \& Silver, E. (1983). Rational number concepts. In R. Lesh \& M. Landau (Eds.). The acquisition of mathematical concepts and processes. New York: Academic Press.

[20] Lesh, R., Landau, M., \& Hamilton, E. (1983). Conceptual models in applied mathematical problem solving." In R. Lesh, The acquisition of mathematical concepts and processes. New York Academic Press.

[21] Lamon, S. J. (2001). Presenting and representing: From fractions to rational numbers. In A. Cuoco (Ed.), The Roles of Representation in School Mathematics (2001 Yearbook). Reston, VA: National Council of Teachers of Mathematics.

[22] Janvier, C. (1987). Representations and understanding: The notion of function as an example. In C. Janvier (Ed.), Problems of Representations in the Learning and Teaching of Mathematics (pp. 67-73). New Jersey: Lawrence Erlbaum Associates.

[23] Lesh, R., Behr, M., \& Post, M. (1987). Rational number relations and proportions. In C. Janvier (Ed.), Problems of representation in the teaching and learning of mathematics (pp. 41-58). Hillsdale, NJ: Erlbaum.

[24] Dehaene S. The number sense. Oxford University Press; New York: 1997
[25] Booth, J. L., \& Siegler, R. S. (2006). Developmental and individual differences in pure numerical estimation. Developmental Psychology, 41, 189-201.

[26] Siegler, R. S., \& Opfer, J. E. (2003). The development of numerical estimation: Evidence for multiple representations of numerical quantity. Psychological Science, 14, 237-243.

[27] Siegler, R. S., \& Booth, J. L. (2004). Development of numerical estimation in young children. Child Development, 75, 428-444. 